This is an unedited manuscript published in the Journal of Career Assessment.

Please note that the published version underwent minor additional editing in style and content.

Complete reference:

Zhang, C., Hirschi, A., \& You, X. (2020). Trajectories of calling in the transition from university to work: A growth mixture analysis. Journal of Career Assessment. doi: $10.1177 / 1069072720931010$

Trajectories of Calling in the Transition from University to Work: A Growth Mixture Analysis

Chunyu Zhang ${ }^{1}$, Andreas Hirschi ${ }^{2}$, and Xuqun You ${ }^{1}$

1 School of Psychology, Shaanxi Normal University, Xi'an, China

2 Institute of Psychology, University of Bern, Switzerland

Author Note

Acknowledgement: This research was supported by National Natural Science Foundation of China (71702092); the Humanity and Social Science Foundation of Ministry of Education of China (17XJC190008); China Postdoctoral Science Foundation (2016M590917); and Shaanxi Province Postdoctoral Science Foundation (2017BSHYDZZ55).

Address all correspondence about this manuscript to Chunyu Zhang, School of Psychology, Shaanxi Normal University, Xi'an, China, chunyu.zhang@snnu.edu.cn 


\begin{abstract}
Research on the development of calling is still in its infancy and rarely focused on how calling changes during a major career transition. The current study examined the developmental trajectories of calling and their relation with personality (i.e., conscientiousness, proactive personality) in the transition from university to work with a three-wave longitudinal study with 340 Chinese graduating university students. Results based on growth mixture modeling indicated three developmental trajectories of calling: high and stable calling ( $23 \%$ of sample), high but decreasing calling (74\%), and low and increasing calling (3\%). Moreover, higher conscientiousness related to a higher chance of being classified into the high and stable calling trajectory. These findings add notable insights to the literature by exploring the previously neglected developmental trajectories of calling and their association with personality in the transition from university to work.
\end{abstract}

Keywords: Calling, university to work transition, developmental trajectory, conscientiousness, proactive personality 


\section{Trajectories of Calling in the Transition from University to Work: A Growth Mixture}

\section{Analysis}

\section{Introduction}

Over the past decade, the notion of calling has drawn great attention in vocational psychology (Brown \& Lent, 2016). Calling refers to a career orientation that is motivated by an external summons or guiding force, and carrying a personal meaning, and prosocial intention (Dik \& Duffy, 2009; Zhang, Dik, Wei, \& Zhang, 2015). Research has predominantly demonstrated that calling relates to positive career, work, and well-being outcomes in university students and working adults (for a review, see Duffy \& Dik 2013). However, few studies have examined how callings change over time (e.g., Dobrow, 2013; Hirschi \& Herrmann, 2013; Hirschi, Keller, \& Spurk, 2019; Vianello, Galliani, Dalla Rosa, \& Anselmi, 2019). Such research would be important because there is an increasing recognition that callings are not static (e.g., Dobrow, 2013; Hirschi et al., 2019). For example, Zhang et al. (2018) found that Chinese university students experienced a decrease in calling over time. Dobrow's (2013) seven-year longitudinal study with music students found that their callings were decreasing over the time span from high school to post-college life (e.g., starting graduate school or work). Understanding how callings might change over time, including what can explain individual differences in such changes, is thus essential to obtain a better understanding of the nature of callings.

Changes in callings might be especially pronounced during major career transitions, because such transitions can trigger important identity change (Super, Savickas, \& Super, 1996). Such identity change is presumably caused by the learning experience when entering a new developmental stage of career (Super et al., 1996). Based on Hall and Chandler's (2005) calling model of career success, dynamics of calling are regarded as emerging from a goal attainment process, in which career goal attainment triggers identity change which is important to drive changes in calling. Hence, if individuals with a calling are unable to achieve their career goals during career transitions (e.g., secure a satisfying job after graduation), their career identities might be altered or weakened, which may in turn reduce their sense of a calling. Conversely, successful career goal attainment during career transitions (e.g., obtaining a job that is perceived as highly meaningful after graduation) could strengthen 
their career identity and their sense of calling. However, calling research has thus far largely neglected how callings might change during career transitions. In the present study, we focus on callings in the transition from university to work - a critical period in career development. In terms of Super's developmental theory (Super et al., 1996; Hartung, 2013), this profound career transition is the phase from a student to a worker, from exploring to establishing a career, to achieve career goals and implement the self in the workplace. We expect that this transition is especially important to trigger changes in calling. Accordingly, the current study explores changes of calling in the transition from university to work, by examining the existence of different trajectories of change in calling in this transition.

Moreover, we address what predicts different calling trajectories by specifically highlighting the predictive effect of personality traits. Personality is broadly recognized as playing an important role in career development and vocational behavior (Brown \& Hirschi, 2013). However, although some research has paid attention to the relation of personality and change of calling (e.g., Zhang, Hirschi, Dik, Wei, \& You, 2018), existing theoretical models do not address how personality traits might effect changes in calling (e.g., Hall \& Chandler, 2005; Duffy, Dik, Douglass, England, \& Velez, 2018). In the current study, we test the proposition that personality traits might have an important effect on how callings change over time. We base this proposition on the proactive motivation model of Parker, Bindl, and Strauss (2010), which fits well with our conceptualization of dynamics in callings as a goal attainment process. Specifically, we presume that conscientiousness and proactive personality are two important traits which influence the process of proactive goal striving because they relate to proactively setting and achieving goals. Research found these traits to be beneficial in the university-to-work transition in terms of attaining career goals after transitioning to work (e.g., Brown, Cober, Kane, Levy, \& Shalhoop, 2006; Egan, Daly, Delaney, Boyce, \& Wood, 2017). Such goal attainment is considered to be important to consolidate and strengthen a calling according to the calling model of career success (Hall \& Chandler, 2005). Accordingly, we expect these traits might predict different calling trajectories in the transition from university to work.

We conducted a three-wave investigation of calling among Chinese university graduates who were transitioning from university to work. In China, an estimated 8.74 million 
students will graduate in 2020 (Ministry of Education of China, 2019). By comparison, back in 2001, this number was only 1.03 million. The reason of this immense increase is that in 1999, China started a policy of university enrollment expansion (Wen, 2005). In addition, China's education is typically seen as examination-oriented (Dello-Iacovo, 2009), emphasizing more high academic achievement, and less exploring the self and personal interests. This may be harmful to Chinese university students' career choice in the transition from university to work and to their calling because a calling was found to be predicted by a clear self-awareness (Zhang et al., 2018). As a result, the transition from university to work can be extremely important and challenging for Chinese university graduates and their perception of calling. Thus, in China's competitive labor market and educational context, investigating Chinese graduating university students and exploring the developmental trajectory of their callings are theoretically and practically relevant to understand the nature of calling and guide a successful transition in a non-Western context.

In sum, our study makes several contributions to the calling literature. First, we broaden the current knowledge of developmental trajectories of calling in the transition from university to work, providing new insights to understand how callings unfold during critical career transitions. Second, our study deepens the current understanding of calling by shedding light on the relation between personality traits and changes of calling. Third, our study provides practical implications for university graduates and career counselors to understand the nature of callings when transitioning from university to work in a non-Western context.

\section{Dynamics in Callings: Theoretical Framing}

Existing theories of calling have rarely directly addressed how callings might change over time and which factors might predict such changes. As one exception, the calling model of career success by Hall and Chandler (2005) conceptualizes callings as embedded in a dynamic goal attainment process, where calling motivates higher goal focus and goal attainment and thereby promotes career success. This success is in turn a driver of change in identity, which can cause a change in calling. Based on this framework, goal attainment and the subsequent change of identity are thus regarded as essential to the dynamics of calling. When individuals achieve their calling pursuits, their enhanced identity may strengthen their 
calling. Conversely, when pursuing a calling does not result in the aspired success, a weakened identity may attenuate their calling.

The more recent Work as Calling Theory (WCT; Duffy et al., 2018) focuses more on the effects of calling rather than its predicators. However, this model also proposes that individuals who perceived a calling strive to live out their calling and doing so results in higher satisfaction and performance. Conversely, if individuals cannot achieve their pursuit of calling, they may experience negative outcomes in career, work, or general life (Gazica \& Spector, 2015). In sum, we herein presume that the dynamics of calling can be understood as resulting from a goal attainment process, where callings motivate individuals to pursue career goals and their attainment, or non-attainment, provides a reinforcement or weakening of their callings.

This theoretical perspective offers a way to understand how callings might change in the university-to-work transition, where many individuals might have one of the first experiences of pursuing and potentially achieving important career goals. Hence, this transition might be especially relevant to the change of calling. As newcomers to the work world, university graduates often face many challenges and constraints that may influence goal attainment, such as changes in their identities from a student to a worker, lack of experience and skills required by organizations, or inaccurate expectations about work life (Ng \& Feldman, 2007; Wendlandt \& Rochlen, 2008). As a result, graduates might vary greatly in their experiences on how they are able to achieve career goals in line with their callings, which could lead to identity changes and subsequent changes in their presence of a calling.

\section{Developmental Trajectories of Calling in the Transition from University to Work}

In the present study, we apply a person-centered analysis (i.e., Growth Mixture Model ; GMM) to examine calling trajectories. This approach assumes that there are subgroups within a sample with distinct developmental patterns (Woo, Jebb, Tay, \& Parrigon, 2018). Specifically, we posit that four developmental trajectories of calling may exist. First, high levels of calling may decrease in the transition from university to work. Several longitudinal studies of calling have demonstrated that high levels of calling are difficult to sustain. For example, Zhang et al. (2018) observed that callings of Chinese university students decreased 
over time and Dobrow's (2013) similarly found that that the callings of music students decreased between high school to after college. This decrease may be particularly pronounced in the transition from university to work because the challenges and constraints faced by many university students after entering the work world (Wendlandt \& Rochlen, 2008) might disturb their career goal attainment and affect their identity, which may decrease their sense of calling. This may explain why intrinsic work values, which are closely linked to calling (Dobrow \& Tosti-Kharas, 2011; Wrzesniewski, McCauley, Rozin, \& Schwartz, 1997), were found to decrease after college and during young adulthood (22-26 years) (Jin \& Rounds, 2012). Thus, when entering into work world, some university graduates' high level of calling may be difficult to sustain and consequently may decrease.

Second, some university graduates' high level of calling may be stable. This is because some individuals with a high level of calling would have the opportunity to attain their career goals and live out their calling when entering into the work world (Duffy \& Autin, 2013; Duffy et al., 2018). Consequently, based on the theoretical framework of Hall and Chandler (2005), their identity would be strengthened and thereby they may sustain a high level of calling. In addition, some individuals with a high calling may persist in their calling domain and sustain a high level of calling even if confronted with challenges and constraints after entering into work world. Indeed, Dobrow and Heller (2015) found that individuals with a calling perceived high levels of ability and in turn persisted in pursuing a challenging career. Thus, we posit that one possible trajectory of calling would be high and stable during the transition from university to work.

Third, some university students may have a continuously low calling during the transition from university to work. Research suggests that people differ in their levels of calling and some students might not have a strong sense of calling to begin with, possibly because they have other orientations towards work, such as a job or career orientation which emphasize more on financial rewards or career advancement (Wrzesniewski et al., 1997; Willner, Lipshits-Braziler, \& Gati, 2019). When entering to work roles, some individuals may not reshape their identity and thereby may sustain their low levels of calling. Particularly, because new graduates may have low status and face financial constraints, they may tend to emphasize more extrinsic career rewards (Jin \& Rounds, 2012). Under such circumstances, 
those with a low calling may continuously hold a job or career orientation. Thus, some students with a low initial calling may continuously experience a low calling during the transition from university to work.

Finally, some university graduates with low levels of callings might experience an increase in calling. Such an increase might be promoted by an increase in career goal attainment and reshaped identity (Hall \& Chandler, 2005), such as professional identity clarity during this transition, authentic self-awareness and living tendency, and/or positive work experiences (Dalla Rosa, Vianello, \& Anselmi, 2019; Zhang et al., 2018). For this group of university graduates, the university-to-work transition would thus be a positive and meaningful experience where they can explore and implement their self into the work role (Super et al., 1996; Hall \& Chandler, 2005) and thereby also discern and implement a sense of calling. Taken together, we propose:

Hypothesis 1: Four developmental trajectories of calling exist in the transition from university to work, characterized as (a) high-decreasing, (b) high-stable, (c) lowstable, and (d) low-increasing.

\section{Personality Traits as Predictors of Calling Trajectories}

To examine what might explain individual differences in calling trajectories, we draw on the proactive motivation model by Parker et al. (2010). According to this model, personality traits have important effects on the process of setting and achieving (career) goals. Specifically, conscientiousness and proactive personality are two traits that promote goal engagement and attainment. Conscientiousness is the tendency to be orderly, dutiful, achievement-striving, self-disciplined, and cautious (Johnson, 2014). Proactive personality refers to a behavioral tendency to be unconstrained by situational forces and to influence the environment to attain personal goals (Bateman \& Crant, 1993). Proactive individuals are future-oriented and seek to identify opportunities, show initiative, take action, and persevere in pursuing meaningful changes (Bateman \& Crant, 1993; Crant, 2000). Because the process of transitioning from university to work is essentially implementing a career self-concept and career goals (Super et al., 1996) and goal attainment is one of the key components in the dynamic of calling (Hall \& Chandler, 2005), conscientiousness and proactive personality may serve as two important personality antecedents to changes of calling in this transition. 
Specifically, we argue that conscientious and proactive university students are more likely to be in the high-stable trajectory of calling than in the high-decreasing trajectory. Moreover, conscientious and proactive university students are more likely to be in the lowincreasing trajectory of calling than in the low-stable trajectory. According to the proactive motivation model (Parker et al., 2010), conscientiousness and proactive personality are important traits of predicting goal attainment. Conscientious individuals are hard-working and planned to achieve goals. Proactive individuals are taking control and bring about changes to achieve goals. Thus, these traits may be beneficial to career goal attainment in university graduates. Indeed, conscientiousness was found to be positively related to career exploration (Li, Guan, Wang, et al., 2015), career planning (Rogers, Creed, \& Glendon, 2008), and career success (Ng \& Feldman, 2010). Similarly, proactive personality was also found to be positively related to career exploration (Cai, Guan, Li, et al., 2014), goal attainment (Greguras \& Diefendorff, 2010), and career success (Seibert, Kraimer, \& Crant, 2001). According to the calling model of career success (Hall \& Chandler, 2005), when goals and career success are achieved, a new, and more competent identity is more likely to occur, which in turn sustains and consolidates a calling. Thus, conscientious and proactive university students may have a better basis of experiencing a high and stable calling. Conscientious and proactive university students who have a low initial level of calling may have a chance of discerning and increasing a sense of calling because of the goal attainment and identity change.

Hypothesis 2: (a) Conscientiousness and (b) proactive personality are positively related to being categorized in high-stable trajectory of calling rather than highdecreasing trajectory.

Hypothesis 3: (a) Conscientiousness and (b) proactive personality are positively related to being categorized in low-increasing trajectory of calling rather than lowstable trajectory.

\section{Method}

\section{Participants and Procedure}

The data of this study were collected among two large comprehensive universities in China. We first contacted the university administers and staff to obtain their support for our survey and to ensure that the participants can be reached in the follow-up surveys. All 
assessments were conducted as online surveys and the university staff invited students to participate by sending them an invitation and link to the survey via a mobile message. The survey of Time 1 (T1) was conducted at the end of March 2018, three months before graduation when the final semester was started and university students were highly engaging in their job searching. At the end of June, we administered survey of Time 2 (T2), when participants had just graduated from university. Six months later (at the end of December 2018), we administered survey of Time 3 (T3). Perceiving a calling was repeatedly assessed at each wave (T1-T3), whereas conscientiousness and proactive personality were only assessed at T1. Because this study focused on the transition from university to work, we excluded those participants who continued full-time studying at T3. Participants were matched across waves with their student registration numbers. To improve the response rate, we offered 5 China Yuan (CNY) at T1, $10 \mathrm{CNY}$ at T2, and $15 \mathrm{CNY}$ at T3 as an incentive to each participant who provided a valid response.

A total of 1,297 university students were invited, and 1,057 completed the survey at $\mathrm{T} 1($ response rate $=81 \%) ; 65 \%(N=684)$ participated again at $\mathrm{T} 2$; and $32 \%(N=340)$ were remained at T3. The final sample consisted of 340 university students who reported that they had found a job and were working after graduation. Most participants (74\%) self-identified as women. The sample reported a mean age of 23.04 years $(S D=0.95$, ranging from 18 to 26 years) at $\mathrm{T} 1.79 \%$ of the participants reported a major in medicine, and the remaining participants majored in mathematics (including applied mathematics, computing science, and statistics).

We tested the potential impact of "missingness" by creating a dummy variable that separated the participants who participated in less than two waves from those who participated in all three waves (Little, 2013). We found that missingness was nonsignificantly related to perceiving a calling and conscientiousness at $\mathrm{T} 1$. We also found no difference in gender between groups. However, participants who completed less than two waves were somewhat younger $(M=22.8$ vs 23.1 years, $t=3.40, p<.001)$, slightly more proactive $(M=$ 4.61 vs $4.45, t=-3.78, p<.001)$, and more majored in mathematics $\left(\chi^{2}=82.22, p<.001\right)$ than those who participated in all three waves.

\section{Measures}


The English items of the conscientiousness and proactive personality scales were translated into Chinese using procedures suggested by Brislin (1986). Specifically, the items were independently translated into Chinese by the first author. A doctoral student in psychology with excellent English ability was invited to translated the Chinese versions back into English. The first author and another doctoral student in psychology checked the accuracy of the back-translated versions with the original English versions. The final versions were confirmed after a consensus was achieved among the group. Table 1 shows the reliability coefficients, means, and standard deviations for scores on all measures.

Perceiving a calling. The 11-item Chinese Calling Scale (CCS; Zhang, Herrmann, Hirschi, Wei, \& Zhang, 2015) was used, which assesses the perception of calling using three dimensions: guiding force (four items), meaning and purpose (three items), and altruism (four items). Example items are, "I feel that I am destined to pursue my future career." (guiding force) and "My career is one of the means reflecting my life value." (meaning and purpose). The items were answered on a five-point scale that ranged from 1 (strongly disagree) to 5 (strongly agree). Zhang, Herrmann, et al. (2015) reported that the alphas of the total scale ranged from .77 to .84 among three independent Chinese university student samples. The construct validity of the total scale has also been supported by its high correlation with the scores of the Brief Calling Scale (Dik, Eldridge, Steger, \& Duffy, 2012; Zhang, Herrmann, et al., 2015). Prior research has found the CCS to correlate significantly with measures of career decidedness, dispositional hope, authenticity, future work-self salience, life meaning, and life satisfaction (Zhang, Herrmann, et al., 2015; Zhang, Hirschi, Herrmann, Wei, \& Zhang, 2017; Zhang et al., 2018).

Conscientiousness. We used the 24-item conscientiousness subscale from IPIP-NEO120 (Johnson, 2014), assessing six facets of conscientiousness: self-efficacy, orderliness, dutifulness, achievement-striving, self-discipline, and cautiousness. Participants answered on a five-point scale that ranged from 1 (strongly disagree) to 5 (strongly agree). Example items are, "Keep my promises" and "Carry out my plans." We averaged the items to create a total conscientiousness score. Johnson (2014) reported a Cronbach's alpha of .90 of the total scale in a large sample, and demonstrated its good construct validity. The scale has also been demonstrated to have good Cronbach's alpha $(\alpha=.88)$ and construct validity in a Chinese 
sample (Kajonius \& Mac Giolla, 2017). Ge (2016) also confirmed the scale's construct validity and its high correlation with another conscientiousness scale (Big Five Inventory) ( $r$ $=.74$ ) among Chinese university students.

Proactive personality. We used the ten-item version scale of Bateman and Crant's (1993) proactive personality scale (Seibert, Crant, \& Kraimer, 1999). An example item is, "I am always looking for better ways to do things". The seven-point response scale ranged from 1 (strongly disagree) to 7 (strongly agree). Seibert et al. (1999) reported the scale's good internal consistency $(\alpha=.87)$ and its positive associations with career satisfaction and promotions. In studies based on Chinese samples, this scale was found to have good reliability ( $\alpha=.76$ - .90; Hsieh \& Huang, 2014; Liang \& Gong, 2013). Shang and Gan (2009) confirmed this scale's construct validity and its positive association with career decision self-efficacy in Chinese university graduates.

Control variables: We considered several control variables that could influence the trajectories of calling in the transition from university to work. First, we controlled for personjob fit at T3 which was measured with three items ( $\alpha=.86$ in this study) from Cable and DeRue (2002). According to the framework of Hall and Chandler (2005), career goal attainment drives changes in calling and higher person-job fit may represent a sign of career goal attainment (Parker et al., 2010). By controlling for perceived fit after graduation, we can more specifically assess the effects of personality on calling trajectories independent of differences in employment situation after graduation. Second, we controlled for gender $(0=$ male, $1=$ female) because research showed that gender is related to intrinsic work values (e.g., Sortheix, Chow, \& Salmela-Aro, 2015) which are highly correlated with calling (e.g., Dobrow \& Tosti-Kharas, 2011; Wrzesniewski et al., 1997). Third, we controlled for study major $(0=$ medicine, 1 = mathematics $)$ because research suggests that the level of calling can be different across majors (Dobrow \& Tosti-Kharas, 2011). Finally, age was controlled because of its association with calling (e.g., Dobrow \& Tosti-Kharas, 2011; Dobrow, 2013). However, in this study, we found that age and gender were not related to any of the study variables (see Table 1). Study major was positively related to calling, conscientiousness, and proactive personality at $\mathrm{T} 1$. Person-job fit was positively related to calling across all three waves. We controlled for them in the analysis by regressing them on the slope of calling. 


\section{Analytical Approach}

To test whether there are hypothesized classifications for the trajectory of calling in the transition from university to work, we applied a second-order GMM analysis. GMM is used to explore latent trajectory classes, allowing for separating growth models for each latent class, each with its unique estimates of variances and covariate (Grimm \& Ram, 2009; Wickrama, Lee, O’Neal, \& Lorenz, 2016). Instead of analyzing observed variables, a secondorder GMM analyzes the latent variables which are indicated by multiple observed indicators (Grimm \& Ram, 2009; Wickrama et al., 2016). The second-order GMM has unique advantages over GMM (which usually uses single composite scores) because it considers measurement error and allows to evaluate longitudinal invariance which is not possible in GMM (Kim \& Wang, 2017). Consequently, Kim and Wang (2017) found that second-order GMM showed less biased and more accurate class enumeration. Thus, this model is suitable to explore trajectories using multidimensional constructs. We used Mplus (version 7, Muthén \& Muthén 1998-2012) with the robust maximum likelihood estimation MLR to conduct the analyses. The construct of calling was specified as a latent variable indicated by its respective dimensions: guiding force, meaning and purpose, and altruism.

Several fit indices and likelihood-based tests were used to determine the number of classes in GMM (Nylund, Bellmore, Nishina, \& Graham, 2007; Wickrama et al., 2016). First, Akaike's information criterion (AIC) and Bayesian information criterion (BIC) were adopted to choose the best-fitting GMM model. It is recommended that low AIC and BIC values indicate a better model. For the second-order GMM, BIC was particularly recommended to determine the best-fitting model (Kim \& Wang, 2017). Second, the Lo-Mendell-Rubin adjusted likelihood ratio test (LMR-LRT) and the bootstrap likelihood ratio test (BLRT) were adopted to compare the $k$ and $k-1$ class models. A significant $p$ value $(<.05)$ of LMR-LRT and BLRT suggested that the estimated $k$ class model significantly fits better than the $k-1$ class model. Third, an entropy value was used to examine the classification accuracy, providing the percentage of sample accurately classified with a given GMM solution. A higher value of entropy indicated that more cases are accurately classified into their respective GMM classes. Fourth, classification probabilities for the most likely latent class membership were adopted to ascertain the probabilities of classifying cases into each latent classes. It 
indicates that a classification is appropriate if the probabilities of classifying cases to class $\mathrm{k}$ are solely higher and to other classes are all lower. Finally, we considered whether the suggested GMM classes are meaningful and parsimonious.

After extracting the most appropriate number of classes for the trajectories of calling, we conducted multinomial logistic regression analysis in the GMM analysis by including auxiliary variables with the R3STEP procedure (i.e., conscientiousness and proactive personality at $\mathrm{T} 1$ ) to test how they related to the classification into the trajectories of calling (Asparouhov \& Muthén, 2014).

\section{Results}

\section{Descriptive Statistics and Bivariate Correlations}

Table 1 displays the correlation coefficients of all study variables. As shown, calling at T1 was positively related to calling at T2 $(r=.59)$ and T3 $(r=.43)$. On average, participants' calling at $\mathrm{T} 1$ was $3.81(S D=.58)$ on a five-point scale and decreased to 3.74 at $\mathrm{T} 3(S D=.60$; $p<.01)$. Conscientiousness and proactive personality at T1 were all positively correlated with calling at each time point (ranging from $r=.22$ to $.39, p<.01$ ).

\section{Examining Longitudinal Invariance}

We conducted a longitudinal invariance analysis to examine the extent to which measures had equivalent meaning and structure across time points (Little, 2013). Partial strong invariance (intercept invariance) is considered sufficient for conducting GMM analyses (Wickrama et al., 2016). The residual variances of same indicators were correlated across time points in the baseline model. The fit of this model was acceptable (see Table 2). As suggested, the comparative fit index (CFI) and the Tucker-Lewis index (TLI) were greater than .90, and the root-mean-square error of approximation (RMSEA) and the standardized root-meansquare residual (SRMR) were lower than .08 (Little, 2013). Constraining the indicator factor loadings to be equal across time points did not significantly decrease the fit given that the corrected scaled difference test was nonsignificant, $\triangle \mathrm{CFI} \leqslant .010, \triangle \mathrm{RMSEA} \leqslant .015$, and $\triangle \mathrm{SRMR} \leqslant .010$ (Satorra \& Bentler, 2001; Cheung \& Rensvold, 2002; Chen, 2007). Thus, metric invariance was supported. The unstandardized factor loadings were 1.000 (altruism), 1.002 (guiding force), and 1.294 (meaning and purpose). However, constraining the intercepts of indicators to be equal across time points significantly decreased the fit, compared to metric 
invariance. Thus, full strong longitudinal invariance was not supported. Modification indices showed that the intercept of guiding force varied over time and we thus relaxed the constraints on the intercept of guiding force. Because we expected that callings might change in the transition from university to work and we were interested in examining such change patterns (i.e., trajectories), partial strong invariance is sufficient to conduct longitudinal analyses (Little, 2013; Wickrama, Lee, O’Neal, \& Lorenz, 2016), as also done in prior longitudinal studies which explored developmental trajectories (e.g., Boyce, Wood, Daly, \& Sedikides, 2015).

\section{Determining Latent Growth Classes}

We specified GMM models ranging from 2- to 4-classes. Table 3 presents their fit indices and likelihood-based tests. For the 2-class model, AIC, BIC, and SSABIC values were the highest and entropy value was the lowest in all the models. Thus, the 2-class model was rejected. Based on the significance of LMR-LRT value and entropy value, the 3-class model performed better than the 2-class model. Moreover, the 4-class model performed no better than the 3-class model. Thus, the 4-class model was rejected. Based on these considerations, the 3-class model was the best solution, with lower AIC, BIC, SSABIC, higher entropy value, proper classification probabilities for the most likely latent class membership, and explainable and parsimonious classifications. As shown in Table 3, the first class included 252 (74\%) participants, characterizing a high-decreasing group, in which the intercept of calling was high while the slope of this trajectory was significantly negative. The second class included 79 (23\%) participants, characterizing a high-stable group, in which the intercept of calling was high and the slope was nonsignificant. The third and last class included $9(3 \%)$ participants, characterizing a low-increasing group, in which the intercept of calling was low and the slope was significantly positive. This results partly supported Hypothesis 1 as confirmed the existence of three distinct calling trajectories. However, we did not find a classification with low and stable levels of calling. ${ }^{1}$

Predictive Analysis of Conscientiousness and Proactive Personality

\footnotetext{
${ }^{1}$ We also conducted post-hoc analyses to test if the growth trajectories are linear vs. quadratic. The results support a linear growth trajectories of calling.
} 
We then applied multinomial logistic regression analysis for testing the relation between the examined personality variables conscientiousness and proactive personality and the classification probabilities into different calling trajectories. We used the high-stable group as the reference group. Because of the low sample size in the low-increasing group, we excluded this group in the analysis. The results showed that conscientiousness, but not proactive personality, significantly predicted the classification into calling trajectories. Participants with higher conscientiousness (estimate $=-1.03, S E=.37, t=-2.78, p<01$, odd ratios $=.36$ ), but not proactive personality (estimate $=-.26, S E=.23, t=-1.14, p>05$, odd ratios $=1.30$ ), had a significantly higher likelihood of being classified into the high-stable group than into the high-decreasing group, supporting Hypothesis 2a but not 2b. A unit increase in the score on conscientiousness reduced the odds of being classified into the highdecreasing group by about 2.78 times (1/.36). Moreover, hypothesis $3 \mathrm{a}$ and $3 \mathrm{~b}$ were not tested because of the absence of a low-stable group.

\section{Discussion}

Focusing on university graduates' transition from university to work, this study aimed to explore the developmental trajectories of calling and their personality antecedents. Using a three-wave longitudinal design, we investigated a sample of Chinese university graduates who were experiencing the transition from university to work. Our findings revealed that three trajectories of calling exist: high-stable, high-decreasing, and low-increasing. Moreover, conscientious university graduates were more likely to be categorized in the high-stable trajectory rather than the high-decreasing trajectory. These findings add notable insights to the literature that explores the developmental pattern of calling, particularly in the phase of experiencing major life and career transitions, such as the transition from university to work.

The first contribution of this research is to better understand the dynamics of calling during the transition from university to work. Although prior research has explored the development of calling (e.g., Hirschi \& Herrmann, 2013; Zhang et al., 2018; Vianello et al., 2019), we are not aware of any previous study addressing changes of calling in a major life/ career transition. Our findings extend the current knowledge of calling's developmental pattern generally and during a major career transition (i.e., the transition from university to work) more specifically. By exploring the trajectories of calling, our study thus contributes to 
a better understanding calling from a dynamic perspective. As such, our findings can enrich the theoretical framework of Hall and Chandler (2005) and the WCT (Duffy et al., 2018) by adding knowledge on how individual differences in personality traits can predict how people change their callings during major career transitions. In addition, our findings provide new insights into callings in a Chinese context, that is characterized by a very competitive employment market for university graduates (Ministry of Education of China, 2019) and an examination-oriented educational background (Dello-Iacovo, 2009). Although the general features of calling in a Chinese context were found to similar to those in a Western context, there seems to be less emphasis on religious roots and more on sense of duty as guiding forces of calling in a Chinese context (Zhang, Dik, et al., 2015). As a result, the trajectories of calling in a Chinese context might be different from those in a Western context. Thus, our findings add to understand the development of calling in non-Western students' transition from university to work.

Our study also extends prior research on the dynamic of calling which focused on its general rate of change (e.g., Dobrow, 2013; Zhang et al., 2018). By applying a personcentered view, in our study, we found three developmental trajectories of calling. Thus, to more fully understand calling and its change, applying a person-centered approach is necessary. We advocate more calling research using such an approach in future research. The first trajectory characterized by high initial levels of calling but a decrease over time (highdecreasing), suggests that for the majority of students with a strong sense of calling at university, this high level of calling is hard to sustain during the transition from university to work. This finding is in line with prior research which has found a general decreasing trend of calling over time within different samples (e.g., Dobrow, 2013; Zhang et al., 2018). Our study suggests that such declines are also frequent in the transition from university to work when many students are experiencing identity change and reality constraints on career goal attainment (Hall \& Chandler, 2005; Ng \& Feldman, 2007; Wendlandt \& Rochlen, 2008). The second trajectory was characterized by high initial levels of calling which remained stable over time (high-stable), suggesting that some university students with high calling are able to sustain a stable and high calling after graduation. This may be because these university students have achieved their career goals or lived out their calling. Or else, even when they 
have not, some individuals with a calling might still persist in their calling (Dobrow \& Heller, 2015). Our results suggest that high levels of calling can be quite persistent over time for some graduates, even as many might experience a major change in their life and work context. The third trajectory was characterized by a low initial level of calling that increased after graduation (low-increasing). This suggests that a small number of university students increasingly discern and perceive their callings when transitioning to work. This may be because, in career transitions the new work experiences provide an opportunity to reshape the self and career perceptions (Super et al., 1996; Hall \& Chandler, 2005). Overall, these results indicate that different students show different developmental trajectories of calling in the transition from university to work. Our results suggest that callings to mostly decrease for university graduates as they enter into the workforce but still others stay stable or possibly even increase. It thus seems that during the transition from university to work, sustaining a high calling or increasing a low calling is not easy. Future theoretical and empirical research on calling should thus examine callings in contexts that include major career changes (e.g., school-to-work, becoming unemployed, retirement) and examine existing trajectories of callings under such circumstances.

The second contribution of this research is the exploration of personality antecedents of calling's developmental trajectories. Our study provides a better understanding of how personality traits relate to the dynamic of calling generally and in the transition from university to work specifically. Our results showed that conscientious university graduates are more likely to be classified into the high-stable trajectory rather than to the high-decreasing trajectory, suggesting that conscientiousness is an important personality trait to develop and sustain a high calling and prevent it from decline. This may be because conscientious individuals have a better basis of achieving career goals that are essential to consolidating a calling (Hall \& Chandler, 2005; Parker et al., 2010). However, proactive personality was not found to relate to calling trajectories. A possible explanation is that, based on the proactive motivation model (Parker et al., 2010), although both conscientiousness and proactive personality are beneficial to achieving goals, the role of proactive personality is less important than conscientiousness because proactive personality has a strong situational-change focus, whereas the development of calling might be more about changing the self rather than the 
situation (Elangovan, Pinder, \& McLean, 2010; Hall \& Chandler, 2005). Although the predictive role of proactive personality on the trajectories of calling was not supported, its role in the dynamics of calling might exist in other ways. For example, students with a proactive personality might be better able to implement their callings and proactivity might thus moderate the effects of calling on outcomes (Duffy et al., 2018). Overall, these findings suggest that some specific personality traits are related to the development and sustainability of a calling. Future research should further explore the predictors and consequences of changes in calling, particularly in major life or career transitions, to deepen the understanding of why calling changes and how such changes affect work, career, and nonwork outcomes.

\section{Limitations and Future Research}

Several possible limitations of the present study should be considered when interpreting our findings. First, our results were analyzed based on a time lag of nine months with three time points. Such time lag was found to be sufficient to capture the university-towork transition (e.g., Brown et al., 2006). However, this time lag is relatively short. We thus recommend that future research tests the developmental trajectory of calling in the transition from university to work using a longer time lag to more fully capture its change pattern. Second, we did not assess participants' job status after the transition to work, such as their work positions, salaries, working hours, or job characteristics. We controlled for person-job fit after transitioning to work in the analysis. However, future research should consider more other job status variables because they may potentially affect the changes in calling after graduation. Third, our sample size was relatively small, resulting in a subsequent small sample size in each change-class, particularly in the low-increasing and high-stable groups. Thus, we advocate future research to use larger samples to explore the trajectories of calling. Fourth, longitudinal strong invariance was not fully supported in our study. This may be because participants' callings were assessed across a major life transition, a period of shifting from a student to a worker and reshaping career perceptions. Although partial strong invariance was suggested to sufficient to conduct longitudinal analyses (e.g., GMM, Wickrama et al., 2016) and was used in prior longitudinal studies which explored developmental trajectories (e.g., Boyce, Wood, Daly, \& Sedikides, 2015), our results might still be potentially affected by incomplete longitudinal invariance. Fifth, the majority of 
participants in our study majored in medicine. Thus, generalizing our results to other majors should be made with caution. Sixth, our study only focused on two personality traits. Future research can explore how other traits (e.g., self-esteem, neuroticism), attitudes (e.g., career self-efficacy), or contextual factors (e.g., social support) affect the developmental trajectories of calling. Finally, our findings were based on a sample of Chinese university graduates. Given of the difference of cultural and educational context between China and Western countries (Dello-Iacovo, 2009; Guan, Chen, Levin, et al., 2015; Willner, Gati, \& Guan, 2015) and its influence on the perception and change of calling (Zhang, Dik, et al., 2015), the generalizability of our findings to other contexts should be made with caution. We advocate more research on exploring the developmental trajectories of calling in the transition from university to work across diverse cultures.

\section{Implications for Practice}

Practically, our findings have implications for university graduates who are undergoing the transition from university to work. First, university students with high calling should realize that their calling could be challenged and decrease when entering into work life. To maintain their calling, career counselors could play a supportive role in assisting university students to deal with this transition (Wendlandt \& Rochlen, 2008). Several practical approaches have been proposed (e.g., Ng \& Feldman, 2007; Wendlandt \& Rochlen, 2008), career counselors could integrate them with the practical frameworks of calling (e.g., Adams, 2012; Dik, Duffy, \& Eldridge, 2009) to preserve and promote a calling in the transition from university to work. For example, counselors can help university students to deepen their callings before graduation by reflecting on sources of calling, connections between their career and life meaning, and identifying prosocial intentions that could be fulfilled through their career (Adams, 2012; Dik et al., 2009). To maintain a calling after the transition to work, counselors could guide university students to collect accurate information about job opportunities, develop proper expectations regarding the world of work, strengthen job skills through work experiences, and identify resources for support and coping (Wendlandt \& Rochlen, 2008). Second, our results indicate that conscientious university graduates with a high level of calling are more likely to sustain a stable sense of calling. Training interventions to support students in enacting a calling could thus help individuals to be act more 
conscientious (e.g., Magidson, Roberts, Collado-Rodriguez, \& Lejuez, 2014). For example, Magidson et al. (2014) applied a behavioral activation intervention to increase behaviors that reflected conscientiousness. Such interventions may also be helpful for sustaining the perception of a calling in the transition from university to work. 


\section{References}

Adams, C. M. (2012). Calling and career counseling with college students: Finding meaning in work and life. Journal of College Counseling, 15, 65-80. doi: 10.1002/j.21611882.2012.00006.x

Asparouhov, T., \& Muthén, B. (2014). Auxiliary variables in mixture modeling: Three-step approaches using Mplus. Structural Equation Modeling, 21, 329-341. doi: $10.1080 / 10705511.2014 .915181$

Bateman, T. S., \& Crant, J. M. (1993). The proactive component of organizational behavior: A measure and correlates. Journal of Organizational Behavior, 14(2), 103-118. doi: $10.1002 /$ job.4030140202

Brislin, R. W. (1986). The wording and translation of research instruments. In W. J. Lonner \& J. W. Berry (Eds.), Cross-cultural research and methodology series, Vol. 8. Field methods in cross-cultural research (pp. 137-164). Thousand Oaks, CA, US: Sage Publications, Inc.

Brown, D. J., Cober, R. T., Kane, K., Levy, P. E., \& Shalhoop, J. (2006). Proactive personality and the successful job search: A field investigation with college graduates. Journal of Applied Psychology, 91, 717-726. doi: 10.1037/0021-9010.91.3.717

Brown, S. D., \& Hirschi, A. (2013). Personality, career development, and occupational attainment. In S. D. Brown \& R. W. Lent (Eds.), Career development and counseling: Putting theory and research to work (2nd ed., pp. 299-328). New York: John Wiley \& Sons.

Boyce, C. J., Wood, A. M., Daly, M., \& Sedikides, C. (2015). Personality change following unemployment. Journal of Applied Psychology, 100(4), 991-1011. doi: $10.1037 / \mathrm{a} 0038647$

Brown, S. D., \& Lent, R. W. (2016). Vocational psychology: Agency, equity, and well-being. Annual Review of Psychology, 67, 541-565. doi:10.1146/annurev-psych-122414033237

Cai, Z., Guan, Y., Li, H., Shi, W., Guo, K., Liu, Y., . . Fang, Z. (2015). Self-esteem and proactive personality as predictors of future work self and career adaptability: An examination of mediating and moderating processes. Journal of Vocational Behavior, 
86, 86-94. doi: 10.1016/j.jvb.2014.10.004

Cable, D.M., \& De Rue, D.S. (2002). The convergent and discriminant validity of subjective fit perceptions. Journal of Applied Psychology, 87, 875-884. doi: 10.1037//00219010.87.5.875

Chen, F. F. (2007). Sensitivity of goodness of fit indexes to lack of measurement invariance. Structural Equation Modeling: A Multidisciplinary Journal, 14(3), 464-504. doi: $10.1080 / 10705510701301834$

Cheung, G. W., \& Rensvold, R. B. (2002). Evaluating goodness-of-fit indexes for testing measurement invariance. Structural Equation Modeling, 9, 233-255. doi:10.1207/S15328007SEM0902_5

Crant, J. M. (2000). Proactive behavior in organizations. Journal of Management, 26, 435462. doi: 10.1177/014920630002600304

Dalla Rosa, A., Vianello, M., \& Anselmi, P. (2019). Longitudinal predictors of the development of a calling: New evidence for the a posteriori hypothesis. Journal of Vocational Behavior, 114, 44-56. doi: 10.1016/j.jvb.2019.02.007

Dello-Iacovo, B. (2009). Curriculum reform and 'Quality Education' in China: An overview. International Journal of Educational Development, 29, 241-249. doi: 10.1016/j.ijedudev.2008.02.008

Dik, B. J., \& Duffy, R. D. (2009). Calling and vocation at work: Definitions and prospects for research and practice. The Counseling Psychologist, 37, 424-450. doi:10.1177/0011000008316430

Dik, B. J., Duffy, R. D., \& Eldridge, B. M. (2009). Calling and vocation in career counseling: Recommendations for promoting meaningful work. Professional Psychology: Research and Practice, 40(6), 625-632. doi:10.1037/a0015547

Dik, B. J., Eldridge, B. M., Steger, M. F., \& Duffy, R. D. (2012). Development and validation of the Calling and Vocation Questionnaire (CVQ) and Brief Calling Scale (BCS). Journal of Career Assessment, 20, 242-263. doi: 10.1177/1069072711434410

Dobrow, S. R. (2013). Dynamics of calling: A longitudinal study of musicians. Journal of Organizational Behavior, 34, 431-452. doi:10.1002/job.1808

Dobrow, S. R. \& Heller, D. (2015). Follow your heart or your head? A longitudinal study of 
the facilitating role of calling and ability in the pursuit of a challenging career. Journal of Applied Psychology, 100(3), 695-712. doi: 10.1037/a0038011

Dobrow, S. R., \& Tosti-Kharas, J. (2011). Calling: The development of a scale measure. Personnel Psychology, 64, 1001-1049. doi:10.1111/j.1744-6570.2011.01234.x

Duffy, R. D., \& Autin, K. L. (2013). Disentangling the link between perceiving a calling and living a calling. Journal of Counseling Psychology, 60, 219-227. doi: $10.1037 / \mathrm{a} 0031934$

Duffy, R. D. \& Dik, B. J. (2013). Research on calling: What have we learned and where are we going? Journal of Vocational Behavior, 83, 428-436. doi: 10.1016/j.jvb.2013.06.006

Duffy, R. D., Dik, B. J., Douglass, R. P., England, J. W., \& Velez, B. L. (2018). Work as a calling: A theoretical model. Journal of Counseling Psychology, 65(4), 423-439. doi: $10.1037 / \operatorname{cou} 0000276$

Egan, M., Daly, M., Delaney, L., Boyce, C. J., \& Wood, A. M. (2017). Adolescent conscientiousness predicts lower lifetime unemployment. Journal of Applied Psychology, 102(4), 700-709. doi: 10.1037/ap10000167

Elangovan, A. R., Pinder, C. C., \& McLean, M. (2010). Callings and organizational behavior. Journal of Vocational Behavior, 76, 428-440. doi:10.1016/j.jvb.2009.10.009

Gazica, M. W., \& Spector, P. E. (2015). A comparison of individuals with unanswered callings to those with no calling at all. Journal of Vocational Behavior, 91, 1-10. doi: 10.1016/j.jvb.2015.08.008

Ge. P. (2016). Psychometric properties of the Chinese version of the IPIP-NEO-120. Yangzhou University, Jiangsu, China. Unpublished master's thesis.

Greguras, G. J., \& Diefendorff, J. M. (2010). Why does proactive personality predict employee life satisfaction and work behaviors? A field investigation of the mediating role of the self-confidence model. Personnel Psychology, 63(3), 539-560. doi:10.1111/j.1744-6570.2010.01180.x

Grimm, K. J., \& Ram, N. (2009). A Second-Order Growth Mixture Model for Developmental Research. Research in Human Development, 6(2-3), 121-143. doi:10.1080/15427600902911221 
Guan, Y., Chen, S. X., Levin, N., Bond, M. H., Luo, N., Xu, J., ... Han, X. (2015).

Differences in career decision-making profiles between American and Chinese university students: The relative strength of mediating mechanisms across cultures. Journal of Cross-Cultural Psychology, 46(6), 856-872. doi:

$10.1177 / 0022022115585874$

Hall, D. T., \& Chandler, D. E. (2005). Psychological success: When the career is a calling. Journal of Organizational Behavior, 26, 155-176. doi:10.1002/job.301

Hirschi, A., \& Herrmann, A. (2013). Calling and career preparation: Investigating developmental patterns and temporal precedence. Journal of Vocational Behavior, 83, 51-60. doi: 10.1016/j.jvb.2013.02.008

Hirschi, A., Keller, A. C., \& Spurk, D. M. (2019). Calling as a double-edged sword for worknonwork enrichment and conflict among older workers. Journal of Vocational Behavior, 114, 100-111. doi:10.1016/j.jvb.2019.02.004

Hsieh, H. H., \& Huang, J. T. (2014). The effects of socioeconomic status and proactive personality on career decision self-efficacy. The Career Development Quarterly, 62, 29-43. doi: 10.1002/j.2161-0045.2014.00068.x

Hartung, P. J. (2013). The life-span, life-space theory of careers. In R. W. Lent, \& S. D. Brown (Eds.). Career development and counseling: Putting theory and research to work (pp. 147-183). (2nd ed.). Hoboken, New Jersey: John Wiley \& Sons.

Jin, J., \& Rounds, J. (2012). Stability and change in work values: A meta-analysis of longitudinal studies. Journal of Vocational Behavior, 80, 326-339. doi: 10.1016/j.jvb.2011.10.007

Johnson, J. A. (2014). Measuring thirty facets of the five factor model with a 120-item public domain inventory: Development of the IPIP-NEO-120. Journal of Research in Personality, 51, 78 - 89. doi: 10.1016/j.jrp.2014.05.003

Kajonius, P., \& Mac Giolla, E. (2017). Personality traits across countries: Support for similarities rather than differences. PLoS One, 12(6), e0179646. doi: 10.1371/journal.pone.0179646

Kim, E. S., \& Wang, Y. (2017). Class enumeration and parameter recovery of Growth Mixture Modeling and second-order Growth Mixture Modeling in the presence of 
measurement noninvariance between latent classes. Frontiers in psychology, 8, 1499. doi: 10.3389/fpsyg.2017.01499

Shang, J., \& Gan, Y. (2009). Analysis of the effects of the proactive personality on graduates' career decision-making self-efficacy. Acta Scientiarum Naturalium Universitatis Pekinensis, 45(3), 548-554. doi: 10.13209/j.0479-8023.2009.081

Li, Y., Guan, Y., Wang, F., Zhou, X., Guo, K., Jiang, P., ... Fang, Z. (2015). Big-five personality and BIS/BAS traits as predictors of career exploration: The mediation role of career adaptability. Journal of Vocational Behavior, 89, 39-45. doi: 10.1016/j.jvb.2015.04.006

Liang, J. \& Gong, Y. (2013). Capitalizing on proactivity for informal mentoring received during early career: The moderating role of core self-evaluations. Journal of Organizational Behavior, 34, 1182-1201. doi: 10.1002/job.1849

Little, T. D. (2013). Longitudinal structural equation modeling. New York, NY: Guilford. Magidson, J. F., Roberts, B. W., Collado-Rodriguez, A., \& Lejuez, C. W. (2014). Theorydriven intervention for changing personality: Expectancy value theory, behavioral activation, and conscientiousness. Developmental Psychology, 50(5), 1442-1450. doi: $10.1037 / \mathrm{a} 0030583$

Ministry of Education of China. (2019). China expected to have 8.74 million college graduates in 2020. Retrieved December 29, 2019, from http://en.moe.gov.cn/news/media_highlights/201911/t20191101_406437.html

Muthén, B. O., \& Muthén, L. K. (1998-2012). Mplus user's guide. Seventh edition. Los Angeles, CA: Muthén \& Muthén.

Ng, T. W. H., \& Feldman, D. C. (2007). The school-to-work transition: A role identity perspective. Journal of Vocational Behavior, 71(1), 114-134. doi: 10.1016/j.jvb.2007.04.004

Ng, T. W. H., \& Feldman, D. C. (2010). Human capital and objective indicators of career success: The mediating effects of cognitive ability and conscientiousness. Journal of Occupational and Organizational Psychology, 83(1), 207-235. doi:10.1348/096317909x414584

Nylund, K., Bellmore, A., Nishina, A., \& Graham, S. (2007). Subtypes, severity, and 
structural stability of peer victimization: What does latent class analysis say? Child Development, 78, 1706-1722. doi: 10.1111/j. 1467-8624.2007.01097.x

Parker, S. K., Bindl, U. K., \& Strauss, K. (2010). Making Things Happen: A Model of Proactive Motivation. Journal of Management, 36(4), 827-856. doi:10.1177/0149206310363732

Rogers, M. E., Creed, P. A., \& Ian Glendon, A. (2008). The role of personality in adolescent career planning and exploration: A social cognitive perspective. Journal of Vocational Behavior, 73(1), 132-142. doi: 10.1016/j.jvb.2008.02.002

Satorra. A., \& Bentler. P. (2001). A scaled difference chi-square test statistic for moment structure analysis. Psychometrika, 66, 507-514. doi: 10.1007/BF02296192

Seibert, S. E., Crant, J. M., \& Kraimer, M. L. (1999). Proactive personality and career success. Journal of Applied Psychology, 84(3), 416-247. doi:10.1037/00219010.84 .3 .416

Seibert, S. E., Kraimer, M. L., \& Crant, J. M. (2001). What do proactive people do? A longitudinal model linking proactive personality and career success. Personnel Psychology, 54, 845-874. doi:10.1111/j.1744-6570.2001.tb00234.x

Sortheix, F. M., Chow, A., Salmela-Aro, K. (2015). Work values and the transition to work life: A longitudinal study. Journal of Vocational Behavior, 89, 162-171. doi: 10.1016/j.jvb.2015.06.001

Super D. E., Savickas, M. L., \& Super, C. M. (1996). The life-span, life-space approach to careers. In D. Brown \& L. Brooks (Eds.), Career choice and development: Applying contemporary theories to practice (3rd ed., pp. 121-178). San Francisco, CA: JosseyBass.

Vianello, M., Galliani, E. M., Dalla Rosa, A., \& Anselmi, P. (2019). The developmental trajectories of calling: Predictors and outcomes. Journal of Career Assessment, 28, 128-146. doi: $10.1177 / 1069072719831276$

Wen, D. (2005). The impacts of Chinese higher education expansion on graduate employment: an empirical analysis. Journal of Higher Education, 4, 25-30.

Wendlandt, N. M., \& Rochlen, A. B. (2008). Addressing the college-to-work transition: Implications for University career counselors. Journal of Career Development, 35(2), 
151-165. doi: 10.1177/0894845308325646

Willner, T., Gati, I., \& Guan, Y. (2015). Career decision-making profiles and career decision making difficulties: A cross-cultural comparison among US, Israeli, and Chinese samples. Journal of Vocational Behavior, 88, 143-153. doi:

10.1016/j.jvb.2015.03.007

Wickrama, K. A. S., Lee, T. K., O’Neal, C. W., \& Lorenz, F. O. (2016). Higher-order growth curves and mixture modeling with Mplus: A practical guide. New York: Routledge.

Willner, T., Lipshits-Braziler, Y., \& Gati, I. (2019). Construction and Initial Validation of the Work Orientation Questionnaire. Journal of Career Assessment, 28(1), 109-127. doi:10.1177/1069072719830293

Wrzesniewski, A., McCauley, C., Rozin, P., \& Schwartz, B. (1997). Jobs, careers, and callings: People's relations to their work. Journal of Research in Personality, 31(1), 21-33. doi:10.1006/jrpe.1997.2162

Woo, S. E., Jebb, A. T., Tay, L., \& Parrigon, S. (2018). Putting the "person" in the center: Review and synthesis of person-centered approaches and methods in organizational science. Organizational Research Methods, 21(4), 814-845. doi:10.1177/1094428117752467

Zhang, C., Dik, B. J., Wei, J., \& Zhang, J. (2015). Work as a calling in China: A qualitative study of Chinese college students. Journal of Career Assessment, 23(2), 236-249. doi: $10.1177 / 1069072714535029$

Zhang, C., Herrmann, A., Hirschi, A., Wei, J., \& Zhang, J. (2015). Assessing calling in Chinese college students: Development of a measure and its relation to hope. Journal of Career Assessment, 23(4), 582-596. doi: 10.1177/1069072715595804

Zhang, C., Hirschi, A., Dik, B. J., Wei, J., \& You, X. (2018). Reciprocal relation between authenticity and calling among Chinese university students: A latent change score approach. Journal of Vocational Behavior, 107, 222-232. doi: 10.1016/j.jvb.2018.05.005

Zhang, C., Hirschi, A., Herrmann, A., Wei, J., \& Zhang, J. (2017). The future work self and calling: The mediational role of life meaning. Journal of Happiness Studies, 18(4), 977-991. doi: 10.1007/s10902-016-9760-y 


\section{Table 1}

Correlations, Reliabilities, Means, and Standard Deviations of the Assessed Variables

\begin{tabular}{|c|c|c|c|c|c|c|c|c|c|c|c|}
\hline Variables & M & SD & 1 & 2 & 3 & 4 & 5 & 6 & 7 & 8 & 9 \\
\hline 1. Gender & - & - & - & & & & & & & & \\
\hline 2. Age & 23.04 & .95 & $-.17 * *$ & - & & & & & & & \\
\hline 3. Study major & - & - & $.13^{*}$ & $-.38 * *$ & - & & & & & & \\
\hline 4. Calling $\mathrm{T} 1$ & 3.81 & .58 & .07 & -.01 & $.15 * *$ & .87 & & & & & \\
\hline 5. Calling $\mathrm{T} 2$ & 3.80 & .58 & .07 & .05 & .01 & $.59 * *$ & .89 & & & & \\
\hline 6. Calling $\mathrm{T} 3$ & 3.74 & .60 & -.02 & .06 & .03 & $.43 * *$ & $.56^{* *}$ & .90 & & & \\
\hline 7. Conscientiousness T1 & 3.56 & .46 & .01 & -.06 & $.13 *$ & $.33 * *$ & $.26^{* *}$ & $.22 * *$ & .90 & & \\
\hline 8. Proactive personality $\mathrm{T} 1$ & 4.48 & .66 & -.08 & -.04 & $.11 *$ & $.39 * *$ & $.28 * *$ & $.23 * *$ & $.36^{* *}$ & .84 & \\
\hline 9. Person-job fit T3 & 3.35 & .71 & -.10 & .09 & .05 & $.23 * *$ & $.27 * *$ & $.43 * *$ & $.16^{* *}$ & $.21 * *$ & .86 \\
\hline
\end{tabular}

Note. Numbers in diagonal in italic are the Cronbach's alpha reliability coefficients. $\mathrm{T} 1=$ Time 1 : three months before graduation, $\mathrm{T} 2=\mathrm{Time} 2$ : graduation, T3 = Time 3: six months after graduation. $N=340 .{ }^{*} p<.05 . * * p .01$. 


\section{Table 2}

Fit Information for the Longitudinal Invariance Models

\begin{tabular}{lccccccccc}
\hline \multicolumn{1}{c}{ Models } & S-B $\chi^{2}$ & $d f$ & CFI & TLI & RMSEA & SRMR & $\Delta$ S-B $\chi^{2}$ & $\Delta d f$ & $\Delta$ CFI \\
\hline Configural invariance & 11.97 & 15 & 1.000 & 1.004 & .000 & .024 & \\
Metric invariance & 15.83 & 19 & 1.000 & 1.005 & .000 & .041 & 3.82 & 4 & .000 \\
Strong invariance & 58.51 & 25 & .971 & .958 & .064 & .043 & $44.73^{* * *}$ & 6 & .029 \\
Strong invariance - free guiding force & 35.86 & 23 & .989 & .983 & .041 & .049 & $20.15^{* * *}$ & 4 & .011 \\
\hline
\end{tabular}

Note. $* * * p<.001$.

Table 3 
Comparison of Fit Indices for Growth Mixture Models with 2-4 classes for calling

\begin{tabular}{|c|c|c|c|}
\hline Fit statistics & 2 classes & 3 classes & 4 classes \\
\hline LL (No. of Parameters) & $-3214.89(49)$ & $-3196.04(56)$ & $-3177.51(63)$ \\
\hline AIC & 6527.78 & 6504.08 & 6481.02 \\
\hline BIC & 6715.40 & 6718.50 & 6722.25 \\
\hline SSABIC & 6559.97 & 6540.86 & 6522.40 \\
\hline Entropy & .78 & .84 & 83 \\
\hline LMR-LRT $(p)$ & $43.21(.03)$ & $36.80(.02)$ & $.06(.51)$ \\
\hline $\operatorname{BLRT}(p)$ & $44.27(.00)$ & $37.70(.00)$ & $.06(1.00)$ \\
\hline Group size (\%) Class 1 & $262(77 \%)$ & $252(74 \%)$ & $222(65 \%)$ \\
\hline Class 2 & $78(23 \%)$ & $79(23 \%)$ & $83(25 \%)$ \\
\hline Class 3 & & $9(3 \%)$ & $21(6 \%)$ \\
\hline Class 4 & & & $14(4 \%)$ \\
\hline Intercept (slope) Class 1 & $4.07(-.05 * * *)$ & $4.12(-.07 * * *)$ & $4.12(-.04 * *)$ \\
\hline Class 2 & $4.09(-.02)$ & $4.09(-.01)$ & $4.09(-.01)$ \\
\hline Class 3 & & $2.94(.35 * * *)$ & $4.19(-.41 * * *)$ \\
\hline Class 4 & & & $3.06(.35 * * *)$ \\
\hline
\end{tabular}

Note: $\mathrm{LL}=$ Log-Likelihood value; No. of Parameters = Number of estimated (free) parameters; AIC = Akaike's information criterion; BIC = Bayesian information criterion; SSABIC = Sample Size Adjusted BIC; LMR-LRT = Lo-Mendell-Rubin adjusted likelihood ratio test; BLRT = the bootstrap likelihood ratio test. 
5

4.5

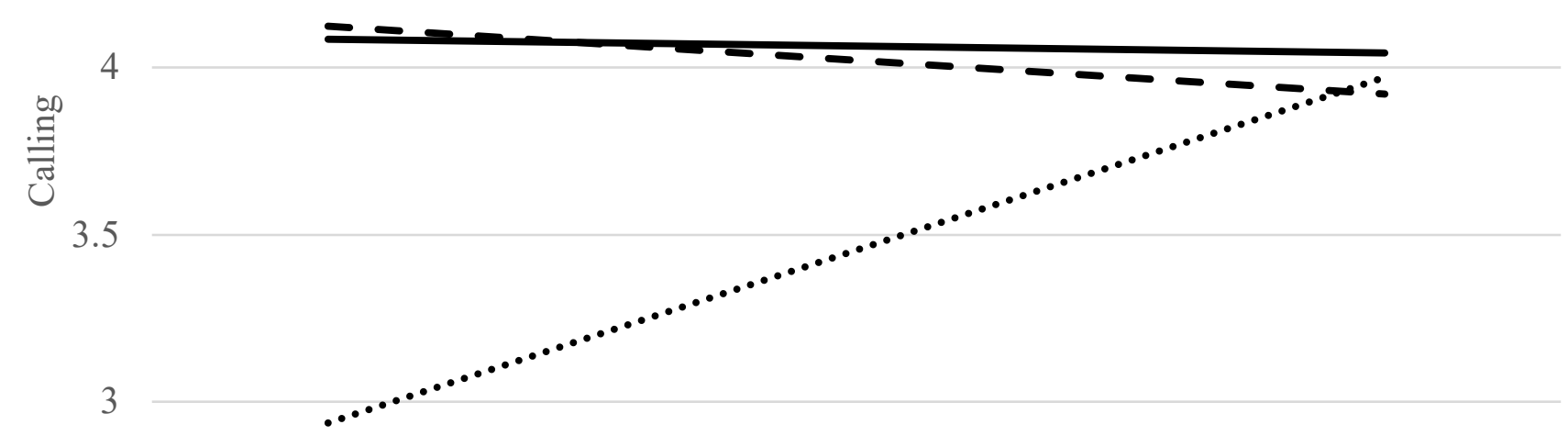

2.5

\begin{tabular}{ccc}
$\begin{array}{c}\text { months before } \\
\text { graduation }\end{array}$ & graduation & $\begin{array}{c}6 \text { months after } \\
\text { graduation }\end{array}$ \\
\hline High-stable & - - High-decreasing & $\cdots . .$. Low-increasing
\end{tabular}

Figure 1. Estimated means of latent trajectory classes for calling in the transition from university to work. 